Article

\title{
Native History and Nation Building on Personal Online Platform: Implications in Hong Kong Context
}

\author{
Simin Li \\ Department of Political Science, University of Victoria, PO Box 2100, Victoria, BC STN CSC, Canada; \\ minsili@uvic.ca
}

Received: 31 December 2018; Accepted: 13 February 2019; Published: 16 February 2019

\begin{abstract}
Nationalism in the era of social media is more complex and presents new opportunities and challenges in different levels and contexts. Therefore, the paper hopes to contribute to understanding the roles of social media in identity presentation and formation in a transition society. Writing on Facebook is a civil practice. Thus, it chooses a typical and clear-cut Facebook fan page "Hong Kong National History" run by a nationalist and followed by over 5700 fans as a case study. Posts of the fan page are collected from 1 April to 31 December in 2017, and it analyzes the contents and forms of posts with content analysis. Then, the self-made digital publication "Hong Kong People's History of the Thousand Years" attached to the fan page is analyzed with narrative analysis. Through the personal systematic discourses, this paper presents a special mode of user-generated content online and a civic Hong Kong story.
\end{abstract}

Keywords: Facebook; localism; Hong Kong

\section{Introduction}

The relationships between media and nationalism are close. Print media help to evoke national consciousness by forming mass readership in a common language (Anderson 2006). Through creating new texts, media develop, record, disseminate, and adapt nationalism (Adria 2009, p. 9). When nationalism becomes a dominant political ideology, it also influences media content (Demertzis et al. 1999, p. 28). To date, the advanced technologies that continue to update and improve the forms and functions of media though traditional media still have a large influence. However, in contrast with regulated mass media's one-way, localized, and limited features, readers can share, debate, and generate content anytime and anywhere through the two-way, boundless, and speedy social media. In addition, they are mobilized and divided by information online. Hence, user is not only the consumer of internet-based media but also the product. The daily usage of mobile devices has indicated that the penetration of print capitalism is extended by digital capitalism (Huijsmans and Trần 2015).

Therefore, nationalism in the era of social media is more complex and presents new opportunities and challenges in different levels and contexts. For non-state actors, online media firstly empowers individuals and marginal groups in society. As a result, fragmented voices and various advocacies that are often ignored or regulated by mass media are heard directly online. Social media provides public space for performing identity (Marichal 2013). When identity is performed, positive and negative emotions that enable online and off-line social movements are displayed (Lin 2017). Moreover, it is viable that virtual belonging is created to bond the faraway citizens and immigrants when a country's diaspora population is around the globe (Lin 2016). The group of "digital diaspora" is proposed and their online behaviors constantly influence the national image (Ding 2007). For instance, Chinese digital diasporas engage with Chinese diasporic nationalism. Political activities, for example, protests, are organized online while assistance is also available by combining domestic and overseas Chinese 
netizens. In addition, confrontational identities are constructed because the accessibility of social media intensifies the existing hatred between groups (Khosravinik and Zia 2014).

However, for those state-sponsored actors and powerful politicians, social media is also a tool to strengthen a narrow and exclusive national identity. The former one is usually organizational and possesses abundant resources while the latter one is personalized and risks the threat to democracy. Disinformation here is manipulated by states or politicians to (re)solidify community (Tynan 2017).

Since nationalism and internet-based media remold each other all the time, the paper seeks to contribute to understanding the roles of social media in identity presentation and formation in a transition society in Asia. After the protests demanding free and fair elections failed in 2014, Hong Kong's democracy and future have faced a deadlock. The traditional ways of political participation seem dysfunctional, whereas a variety of political groups, appeals, and discourses emerge in society. Considering the vibrant digital practices and their potential influences, the paper chooses almost the earliest Facebook fan page with a strong stance that keeps challenging mainstream discourse and has been observed for four years to answer three questions: How does Facebook contribute to the individual writing and disseminating in identity presentation and formation? What are the characteristics of its content generation on Facebook? And what are the implications? The fan page "Hong Kong National History" (HNH) (https:/ / www.facebook.com/hknationalhistory/) is run by a doctor Sing Yan Tsui (Eric) and followed by over 5700 fans. Writing on Facebook is a civil and contextual practice. Through Eric's personal systematic discourses, the paper will present a special mode of content generation and a civic Hong Kong story.

The rest of this paper is structured as follows. Related work is divided into three parts. Literature on narrative as power is introduced first. Then, localism in Hong Kong is reviewed and summarized in detail. In addition, the official and civil historical discourses in Hong Kong are discussed. These are followed by methods of data collection and coding. Then, findings and the meaning of HNH built by Eric are presented. Lastly, limitations of the study and future work are discussed in the conclusion.

\section{Literature Review}

\subsection{Narrative as Power}

Narrative is an action as well as a form to communicate, which ties to experience closely. When experience is expressed in order or its meaning is normalized, it can be viewed as narrative (Bamberg 2012). In brief, narrative can be understood as either a tale or story or a form of talk or writing (Earthy and Cronin 2008). Nevertheless, narrative is also a wider account of social life due to its overarching structure (Wong and Breheny 2018). Through the structure, narrative shapes story itself. Moreover, narrative relies on means. Its various forms include oral expression, text, image, video and so on.

In the digital era, everyone is a narrator whose narratives can be shared, recorded, preserved, and edited online. There is no doubt that content generation online is a narrative. By exchanging narratives, a virtual community can be fostered in a public space (Romney et al. 2017). Furthermore, individuals are a product of discourse in a way from the perspective of social construction (Fearon and Laitin 2000, p. 851). Their behaviors hence are motivated by emotion presented in symbolic vocabulary that can be wielded by politicians (Kaufman 2006).

In the case of $\mathrm{HNH}$, its potential targets can extend beyond Hong Kong even though it is related to Hong Kong nationalism. A larger size of readers online as long as they can read Chinese is available. In addition, successful narratives can affect readers effectively. The effect of persuasion amid the competition of information and attention depends on whose narrative wins. Therefore, bonding the influenced group who have something in common is possible. 


\subsection{Localism in Hong Kong}

Localism is not equivalent to nationalism. Nevertheless, radical localism sometimes is regarded as nationalism (Chan 2016) since nationalism cannot live without local interest. Compared with the implicit Hong Kong nationalism, localism has an explicit clue to trace. Therefore, the section starts from it. Localism as a phenomenon and a term has become a nonnegligible force in Hong Kong in recent years. According to the statistics of Kwong (2016), the number of local newspaper reports that mentioned "localist camp" (bun tou paai), a group of people that prioritize Hong Kong's interest and value, rose suddenly from 2012 and jumped to 1800 in 2015 . The forms of localism refer to a series of social movements, groups and discussions. However, its summit probably was the election of Legislative Council (Legco) in 2016 after the Umbrella Movement, the 79 day-long social protest. Three young localists were elected as legislators successfully. It was also the first formal Legco election ran by pro-democracy and pro-independence candidates.

Nevertheless, localism is not a new issue in Hong Kong. In accordance with different definitions and standards, the evolution of localism in Hong Kong can be traced back to 2007, even in the 1970 s. Before Hong Kong was handed over to China, it had been ruled by the British since the 18th century. However, no substantial boundary was set up in the long term. People out of Hong Kong could move in and out freely. It wasn't until 1950 that the administration started to build up an effective management of the border (Lim 2017). In this period, migrants, the main composition of the population in Hong Kong, hampered the formation of a unique identity. Not until 1966 did the native-born population exceed the population of migrants. Subsequently, with the growth of economy and the public culture, the local identification emerged (Fong 2017a). Law (2015) classifies three waves of local identification.

The first wave appeared at the end of 1960s and spanned the 1970s and 1980s. The baby boomers regarded Hong Kong as their home and struggled with the colonial administration through social movements. However, this local identification was too weak to practice in politics. Hong Kong people as an identity were at best economic men mixed up with China's factors under the non-political governance. When it came to the 1990s, new changes occurred in the second wave under the influence of the Tiananmen Massacre. Rethinking and exploring the relations between Hong Kong and China in culture and politics were mainstream among intellectuals. Hong Kong was viewed as an international city with openness and transnationality by denying the China-centered perspective. After Hong Kong became China's Special Administrative Region, revolts in the circle of culture and art first ignited a new round of protests with the beginning of the third wave. The impactful event must be the anti-Article 23 rally that happened on 1 July 2003. On the one hand, it enlightened plenty of unsatisfied young people known as the "post-1980 generation" by Law (2015). On the other hand, its aftermath made the Beijing government intervene in Hong Kong actively (Chan and $\mathrm{Ng}$ 2017). Since then, the official and civil forces have continued struggling over the long term.

Nevertheless, localism as social movements reappeared in 2007. Initially, these movements were cultural. They aimed at defending Hong Kong's civil memories, heritages and mundane sites-for example, the well-known action of reserving the Star Ferry Pier (Apple Daily 2013). The actors who advocated and launched movements were often reviewed as the first generation with openness and inclusiveness (Chen 2013). However, the turning point came in 2011, albeit the first generation still worked. Featured with anti-mainland sentiment because of the further integration with mainland China in the economy, localism presented a new facet. Ho (2016) called it version 2.0 with exclusiveness and violence.

The most representative example was Chin Wan's discourses in his book "Discourse on the Hong Kong City-State". As a linguist and folklorist, Chin (2011) argues that Hong Kong preserves the original Waa Haa culture and aims to build a confederation. This book has triggered a debate among intellectuals. However, a more noticeable event was the publishing of the magazine "Hong Kong Nationalism" which was run by students of Hong Kong University in 2014. Localism and self-determination were discussed boldly in the magazine. The former Chief Executive Chun-ying 
Leung even criticized its discourses and accused it as an advocacy of independence in a high-profile way (Cheung and So 2015). Hence, the attention to the magazine was increased in society.

New changes have appeared after the Umbrella Movement. Chan and Ng (2017) discovered three trends, namely localization, radicalism and cynicism in society. Hong Kong independence seems not to be a slogan any more. Currently, more and more actions, political groups and voices against the administration and Beijing have been coming out. Even though Hui (2013) argues that the root of localism was the unreasonable distributions of wealth and resources around the globe, the alternative explanation convinces more people. It is the conflict between Hong Kong and Beijing that trigger localism (Cheng 2018; Ming 2015). Likewise, Fong (2017a) argues that the rise of Hong Kong's peripheral nationalism is caused by Beijing's incorporation strategies in politics, economy, and identity. Localism in Hong Kong has become a spectrum with various advocacies and stances.

As the paper mentioned before, localism has reached the summit. Shortly thereafter, a series of disqualifications of the elected Legco members and sentences imposed on a batch of localists followed. Concurrently, the integrations in politics and economy between Hong Kong and mainland China sped up. A doubt was raised regarding whether "One Country Two System" still functions. All these indicate that Hong Kong faces a severe future.

\subsection{Official Discourses versus Civil Discourses}

The sense of a community counts on its members' subjective feelings that come from discursive and symbolic practices (Schneider 2018, p. 45). To be sure, huge disparities between Hong Kong and mainland China in political, economic, law systems, and language are salient, let alone Hong Kong's status of high degree of autonomy being guaranteed. Therefore, a distinct Hong Kong identity exists in the long term, which is a concern of the Beijing government. A Public Opinion Program of Hong Kong University (2018), which has surveyed Hong Kong people's ethnic identity since 1997, finds the feeling of "Hongkongers" remains the strongest while "Chinese" has set a record low since December 2014. Thus, the history education of the school system as a central role in maintaining a stable national identity is highlighted. However, the evolution of Hong Kong history and the relations between Hong Kong and mainland China in text book are complex and nonlinear.

History curricula in Hong Kong schooling basically were depoliticized and decontextualized before the 1970s. Chinese history as a subject that emphasized ancient cultures and traditions was separated from world history, whereas Hong Kong history was absent under the rule of the British (Morris and Vickers 2015). Not until 1996 was Hong Kong native history added into world history. Still, local consciousness is the weakest in textbooks. Wei (2006) summarizes a whole picture of Hong Kong consciousness: China as other but it is never exclusive in ancient Hong Kong. Both connections have lasted for hundreds of years and the indigenous people of Hong Kong stem from mainland China. Currently, as a reaction to the appeal for independence from the younger generation, a revised curriculum guideline is proposed that Chinese history be merged with "Hong Kong development" as an independent subject in junior high school (Chung 2018). At this point, Hong Kong history is still subject to Chinese history.

Beyond the schooling system, Hong Kong's image is also biased and hidden in mainstream discourses. For example, Hong Kong's economic achievement dominates (Gao 2012). Even though civil history is insufficient no matter whether it is in the academic community, school system or society, there are two intellectuals that need to be mentioned. One is the writer Chan Koon Chung. In his long article "90 minutes" social culture history" in 2008, Chan finds that Hong Kong has cultivated a local culture system in advance and identity was formed during the Cold War period (Chu 2015). The other one is folklorist Chin Wan who firstly points out Hong Kong as a city state with a unique history and divides Hong Kong and China in a collected book in 2011 (Chin 2011). This leading thought has elicited different responses in the academic community. Without a doubt, both civil discourses break the official and mainstream perceptions of Hong Kong in government and society. However, these discourses are fragmented and were limited to elites at that time. In contrast, Eric's advocacy in 
academic form is more systematic and advanced. Based on Chin Wan's idea, he moves forward with exploring Hong Kong's subjectivity in history writing (Tsui 2017).

\section{Research Design and Methods}

This section consists of two parts. The first part provides the background and introduction of the fan page and its owner Eric Tsui. The second part is the design and methods. Considering that content sharing is the main component of the posts, in order to enrich the analysis, the paper analyzes a 40-page magazine "Hong Kong People's History of the Thousand Years" created by Eric as well. Hence, it first adopts content analysis to analyze 474 posts of the fan page where data are collected from 1 April to 31 December in 2017 with RStudio and then analyzes the digital magazine attached to HNH with narrative analysis.

\section{The Case of $\mathrm{HNH}$}

Figure 1 shows the homepage of $\mathrm{HNH}$ run by Eric Tsui. Even though the created date is vague, the fan page has been observed over four years online. It is almost the earliest fan page expressing strong nationalism and advocating independence. Its profile picture is a book cover of "A National History of Hong Kong" written by Eric in 2017 and the cover picture is an old photo of Hong Kong. Eric's personal website is also listed on the fan page.

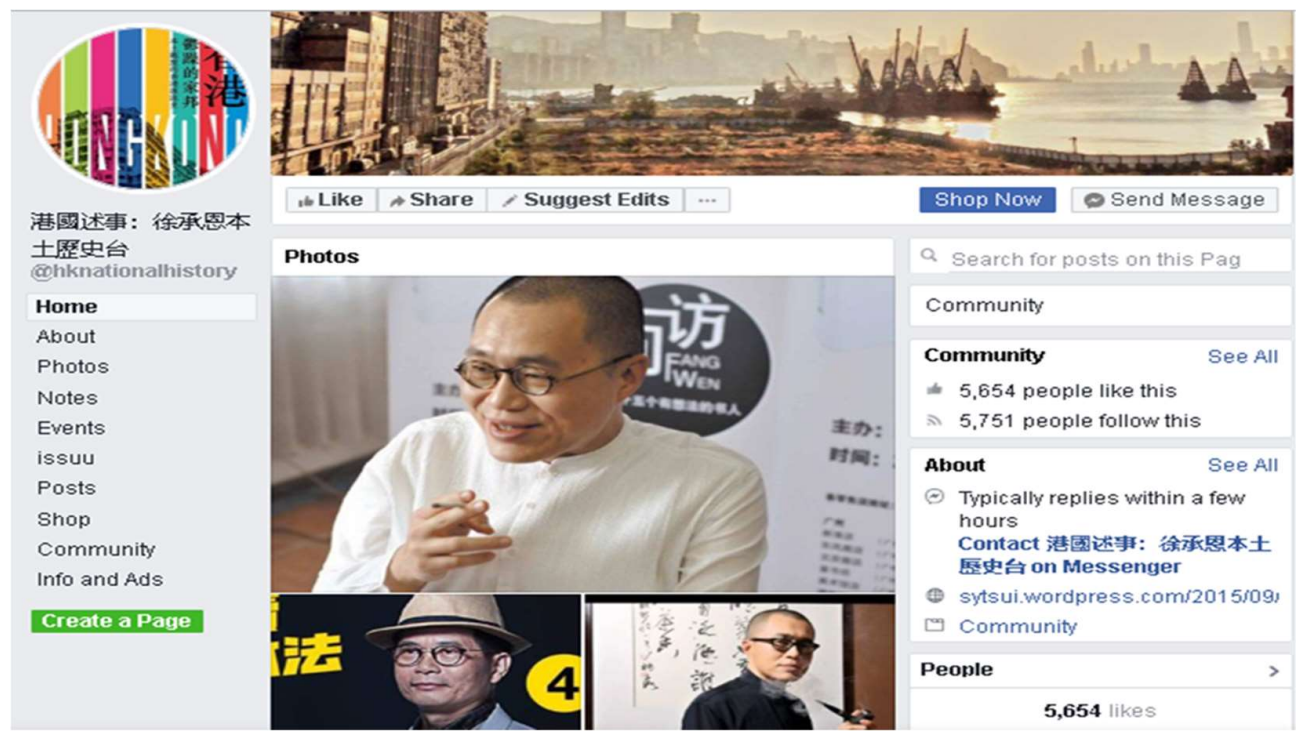

Figure 1. A Screenshot of Fan Page of HNH.

Table 1 shows the basic information of $\mathrm{HNH}$. In its introduction, $\mathrm{HNH}$ is created to share history knowledge and news of four areas, namely Hong Kong, Taiwan, East Asia and Southeast Asia, from a Hong Kong nationalism perspective.

Eric's self-made digital publication "Hong Kong People's History of the Thousand Years" is embedded in the fan page. As for the reference, the number of followers is listed and keeps growing gradually during this period of time.

What is important here is that Eric is a doctor with master's degree of sociology. Before publishing "A National History of Hong Kong" in Taiwan in 2017, he had published four books which focus on localism, relations between Hong Kong and China, and the establishment in Hong Kong as a single author or co-author. In the meantime, he has continued to write for news media outlets and in a personal blog. He often shares his own articles on HNH. In other words, Eric has the ability to form systematic discourses. Furthermore, Eric is a strong nationalist by asserting Hong Kong is a country in his blog, personal Facebook account, and HNH. In his autobiography, he recorded changes 
of attitude to China. Inspired by the book "Imagined Communities" and has realized that he had nothing in common with his classmates from mainland China in the past, Eric gradually formed a stalwart stance. Up to now, faced with the ongoing dilemma in Hong Kong and being angry at the dominated China-centered history writing, he has been dedicated to writing Hong Kong history from a civil perspective (Tsui 2017).

In addition, Eric and his efforts have attracted the attention of the media, academic community, and grass root organizations. He has been classified into the localist camp and his discourses are quoted by academics (Chan 2017). In 2017, he was invited to give a public speech in Taiwan.

Table 1. The basic information of HNH.

\begin{tabular}{ccc}
\hline Category & Content \\
\hline About & $\begin{array}{c}\text { This fan page centers on Hong Kong nationalism and shares history knowledge and } \\
\text { news on Hong Kong, Taiwan, East Asia and Nan Yang. }\end{array}$ \\
Profile Photo \& Cover Photo & Hong Kong People's History of the Thousand Years \\
\hline ISSUU & The number of followers over 5700 \\
\hline Reference
\end{tabular}

\section{Findings}

\subsection{Content Analysis}

Content analysis as a research method has been used widely as a qualitative as well as quantitative research technique. It is a study of messages referring to the meanings, contexts and intentions (Prasad 2008). From 1 April to 31 December, Eric posted 474 posts on Facebook. At least one post was posted per one day within 275 days on average. Tables 2 and 3 are included to specify the content and form of these posts. Each post is an analytical unit. First, this content can be classified into five categories: quoted with/without comment, quoted news/non-news with/without comment, self-created content, private post, and other. In the first and second categories, quotations are shared. Eric quotes others' posts from fan pages, news media, websites and so on with/without his comment. Each quoted text is marked with quotation marks by Eric. The third and fourth ones are created by himself related to history or advocacy. Both are original posts. Especially in the private posts, the propagation of his book and support for certain organizations or persons can be seen. As for the "other" category, it means the less relevant posts including the function of check-in on the map, an update to the cover photo or status and the sharing of an activity without expressing anything.

Table 2. The categories and amount of content of 474 Posts.

\begin{tabular}{ccc}
\hline Content & N & Percentage \\
\hline Quoted with/without comment & 244 & $51.5 \%$ \\
Quoted news/non-news with/without comment & 175 & $36.9 \%$ \\
Self-created content & 8 & $1.7 \%$ \\
Private post & 38 & $8.0 \%$ \\
Other & 9 & $1.9 \%$ \\
\hline
\end{tabular}


Table 3. The types and number of forms of 474 posts.

\begin{tabular}{ccc}
\hline Form & N & Percentage \\
\hline text & 4 & $0.8 \%$ \\
text with photo(s) & 17 & $3.6 \%$ \\
text with web link(s) & 336 & $70.9 \%$ \\
text with photo(s) and web link(s) & 16 & $3.4 \%$ \\
photo(s) & 8 & $1.7 \%$ \\
web link(s) & 61 & $12.9 \%$ \\
status & 2 & $0.4 \%$ \\
\hline
\end{tabular}

As Table 2 shows, the first category, the number of quotations from non-news media is the largest and the quotation from news media ranks second. This content is sourced from others. In contrast, the original posts generated by Eric reach merely 46 . It is clear that his primary intention is to introduce and share knowledge from others.

Table 3 shows the forms of posts in seven types. The setting of Facebook provides a variety of appearances. Texts, images, sounds, and links are merged together. Among these posts, the largest amount are "texts with web links" while the number of pure texts is only 4.

However, readers indeed are more concerned about Eric's own contents and opinions. Table 4 shows that the biggest number of "likes, shares, and comments" on Facebook are all from his original posts. The first post is about the selling of his book "A National History of Hong Kong" published in Taiwan and it attracted 1362 "likes". The most number of "shares" is also from his book itself, which was reprinted by a semi-media outlet called "The News Lens" in Taiwan. As for the most number of "comments", he opposes three main criticisms on the issue of Hong Kong independence and argues that nationalism is a true issue, which evokes the most reflections.

Table 4. The statistics of the most "likes", "shares" and "comments".

\begin{tabular}{lll}
\hline Category & $\mathbf{N}$ & \multicolumn{1}{c}{ Post } \\
\hline Like & 1362 & $\begin{array}{l}\text { "[If you] buy the designated books through "Book Republic" on the website, } \\
\text { for example, [my] 'A national history of Hong Kong', [you] can get 21\% discount } \\
\text { on one book and 25\% discount on two. The promotion period is as of 13 August." }\end{array}$ \\
\hline Share & 55 & $\begin{array}{l}\text { "Thanks to The News Lens reprinted a part of 'A national history of Hong Kong' } \\
\text { and feel free to read." }\end{array}$ \\
\hline & $\begin{array}{l}\text { "The opposition may rebuke 'Hong Kong independence' as a red herring directly } \\
\text { due to the resistance of populist politics and the contradiction with China. } \\
\text { We discuss three criticisms of Hong Kong independence today. The first criticism } \\
\text { argues Hong Kong is merely a city with China's migrants. The second one } \\
\text { argues the imbalances in distribution is the main problem [while independence } \\
\text { is not]. And the last one argues fighting for democracy is more important [than } \\
\text { independence]." }\end{array}$ \\
\hline
\end{tabular}

When it comes to the specific contents themselves, the scopes of the introduced history and news reports are broad. Literature, language, music, election, industry, architecture, movie, crime and so on were mentioned. In this regard, HNH helps to broaden readers' horizons. Nevertheless, at least 68 posts related to the formation and development of localism and national identity in and beyond Hong Kong.

In addition, it finds that six areas are mentioned frequently in three categories (quoted with/without comment, quoted news/non-news with/without comment, self-created content) made up of 427 posts. As Figure 2 shows, Hong Kong (HK) is undoubtedly the most, but Taiwan (TW) is in second place. China (CN) here for Eric is not so close as Taiwan. In HNH's profile, the shared scope is located in East Asia and Southeast Asia. Therefore, Japan (JP), South and North Korea (KN) and Countries in Southeast Asia (SEA) are presented on the fan page. Other subjects, such as Macau, India, Catalonia and themes that cannot be identified are divided into one category. 

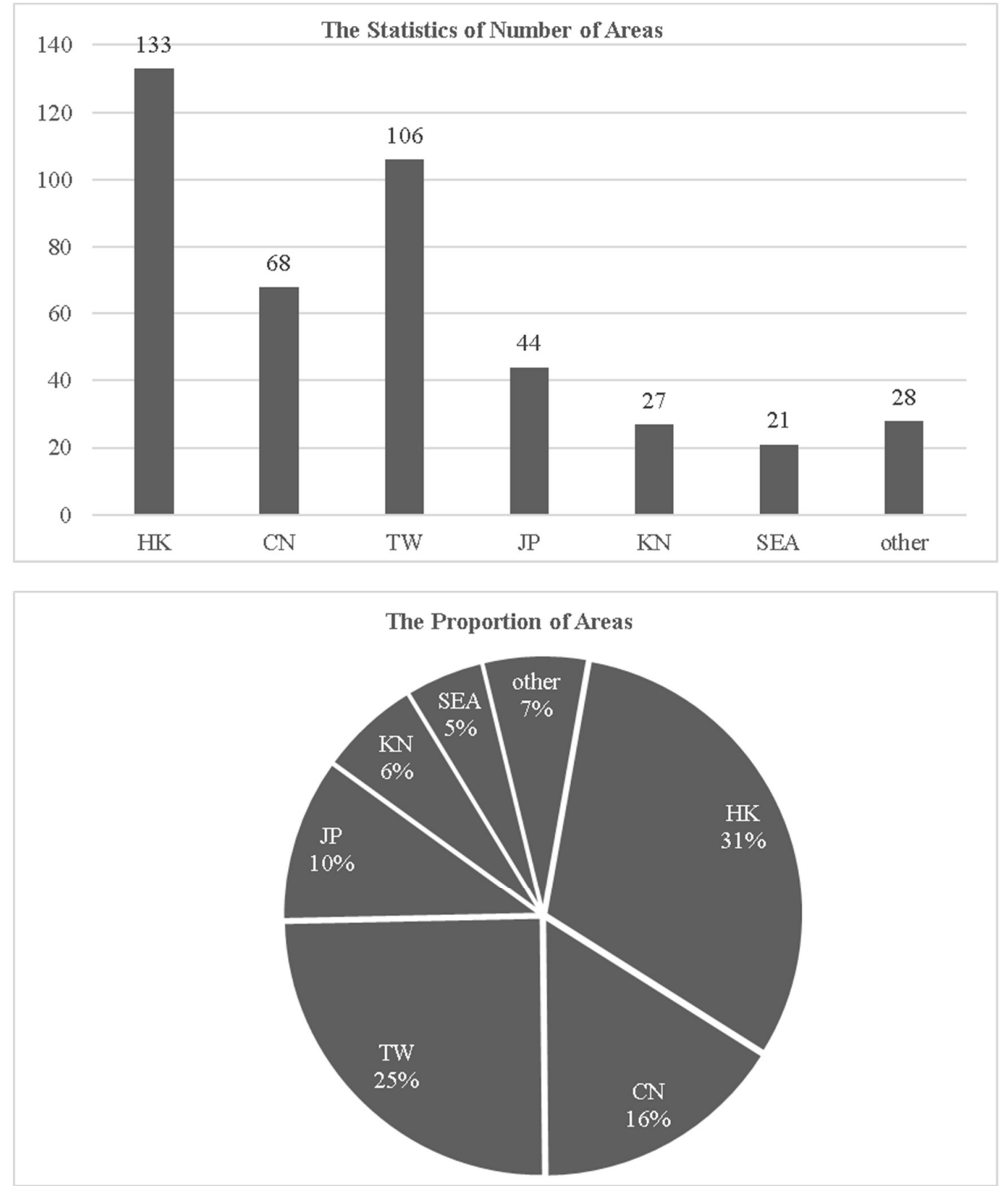

Figure 2. The bar chart and pie chart of the discussed areas of 427 posts.

Another noticeable finding should be the sources of quotation. It can see the might of public writing online. Data are collected from two categories (quoted with/without comment, quoted news/non-news with/without comment). As Figure 3 shows, traditional media with regular journalists and editors are still the most sources. Other normal sources, such as fan page, blog, organizational website (think tank, non-government organization), and professional website (government website) are also used as references. However, the biggest point is sources of self-media and filed writing. This finding embodies a vibrant civil writing online. Both types benefit from the internet and are run by a team of people. Their agendas and target readers are many. In purposive self-media/semi-media, they don't produce news reports. Instead, they reprint news from news media and call for contributors from various fields. In "field writing", it is subject-based creation. For example, one of the websites "who govern", it is run by a batch of learners and researchers in political science aiming at popularizing political knowledge to the public. Such field writing with a 
certain threshold is a digital civil practice as well. Even if those sharings are about history, only one source is from an academic journal.

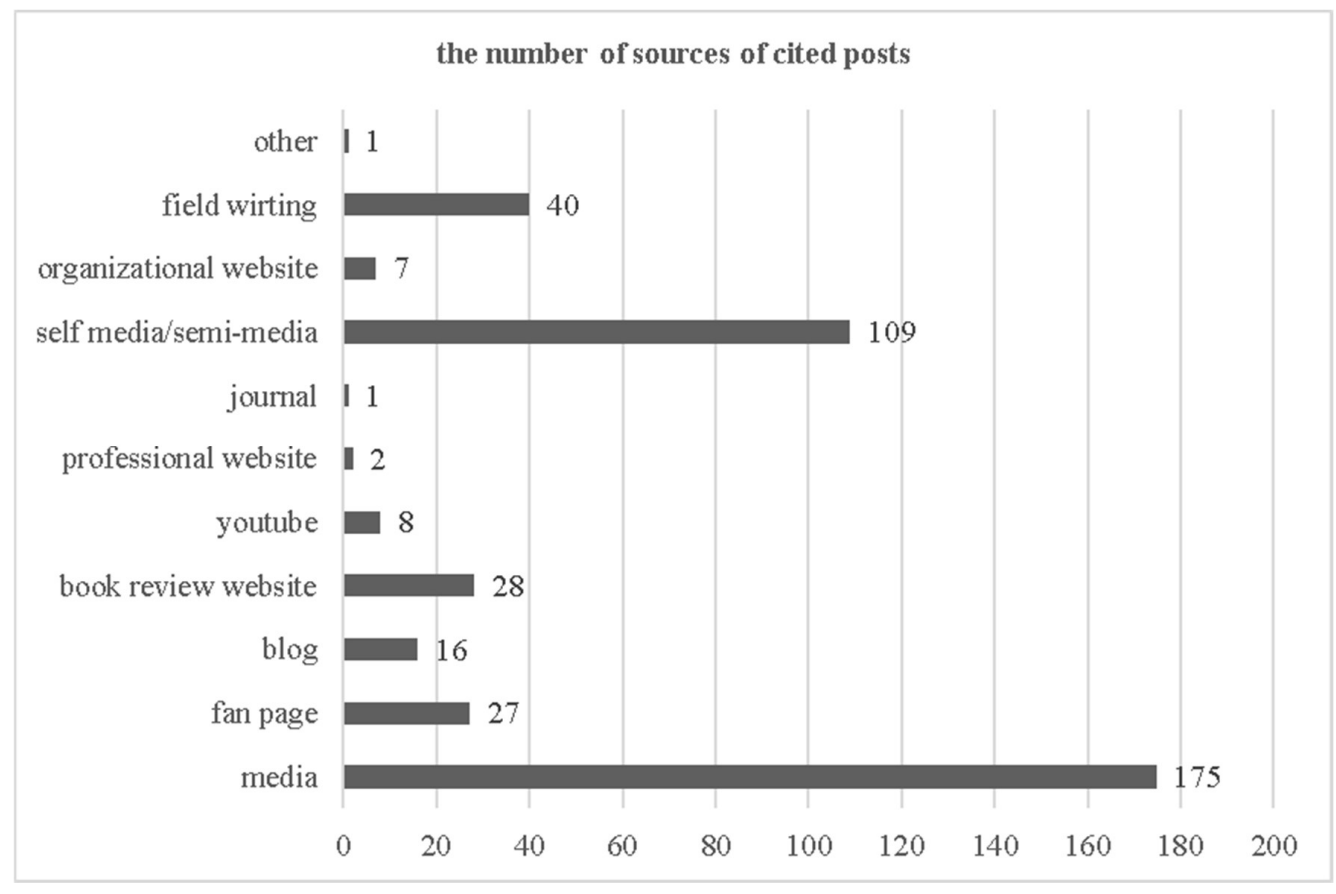

Figure 3. The content sources of 414 quoted posts.

\subsection{Narrative Analysis}

Narrative analysis is an approach to interview data, which explains how and why people tell stories in that way. Identity and interaction between narrator and audience are indispensable (Earthy and Cronin 2008). Compared with text analysis on the text and its structure, social context must be considered in the approach (White and Taket 2000).

Eric's 40-page magazine "Hong Kong People's History of the Thousand Years" attached to the fan page is a brief version of his book "A National History of Hong Kong" in 2015. He has published it as a long essay in the blog and personal Facebook before. In HNH, anyone can download it for free. Figure 4 presents its cover. The term "nation" is used by Eric to describe Hong Kong people even though there is no consensus on this group currently. There are at least three different opinions to define the situation of Hong Kong people. One argues that the Hong Kong nation is fostering. One argues the Hong Kong nation has fostered, and the last one argues that it is quasi-nation. This magazine retells a history from his perspective chronologically. As the paper discusses in the review of official history discourses, Hong Kong's role and subjectivity are absent for a long time. Therefore, Eric proposes new interpretation to present a civil Hong Kong story. According to the rhetoric and the analysis within the magazine, the paper summarizes three themes. 


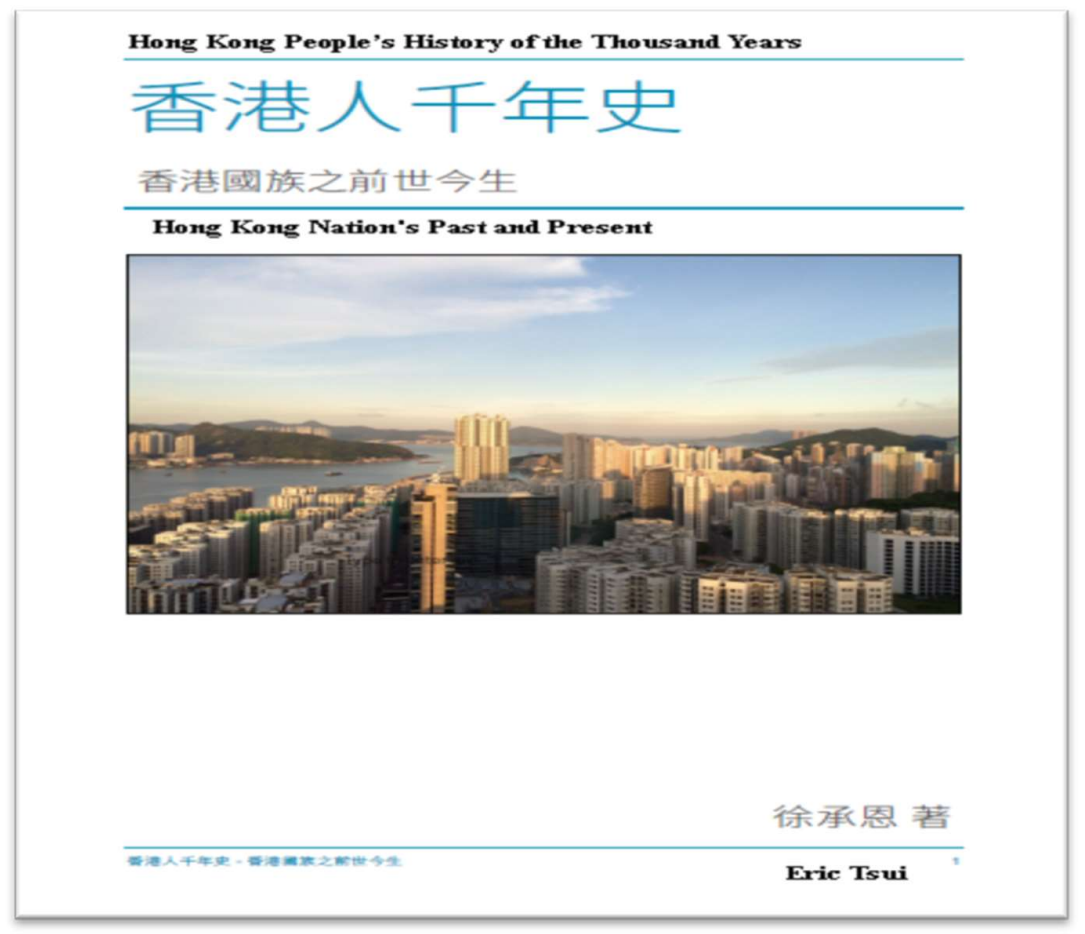

Figure 4. The cover of Eric's self-made magazine.

First, an ocean nation composes and shapes Hong Kong. In the prehistoric era, it is the indigenous people who play a key role in the formation of a port. They are not Han people, who are often regarded as Chinese. Two of four local ethnic groups, namely the Hoklo people and Daan people, as ocean nations are seldomly mentioned in mainstream discourse. However, Eric argues that ocean nations differ from Han Chinese in characteristics and values. They live for maritime business and get rid of Confucian ethnics. In addition, the homosexual group and women are permitted to join in the adventure at sea. Meanwhile, the cooperation with foreigners in trade and war has been prevalent for a long time. The ironic thing is that, most of the time, these ethnic groups living in peripheral regions are marginalized. However, they create an alternative history in contrast with the traditional perception of the Central Kingdom. In short, the original residents in Hong Kong are not Chinese in terms of ethnicities and values. In addition, their extroverted and inclusive traits pave the way for an international city.

Second, the tie to the Central Kingdom is thin historically. In official discourses, Hong Kong has been a part of China historically. However, Eric points out the governance is not always stable and effective due to the failure in assimilation. Even though a governance model is built, rebellions even in indigenized regimes still occur constantly. Only until Ming Dynasty, Sinicization started to work. As has been mentioned before, indigenous people are excluded by the system. Therefore, in order to purchase lands, the residents falsify the family tree to prove that their ancestors are Han people from the north.

Third, the local identification has been longstanding since the 19th century. In the review section of localism in Hong Kong, the paper traces localism back to the 1970s. However, Eric pushes further forward to the end of the 19th century. A small group of elites' identities are mixed in Hong Kong at that time. On the one hand, they have realized the differences with Chinese people in the Qing empire. On the other hand, their loyalty to Qing empire remains. Nevertheless, the common feature of this group is having Hong Kong as a home. Once the conflict with China appears, they turn to collude with the colonial government to fight for Hong Kong's interest. However, the astonishing fact is that the local identification in Hong Kong never vanishes, no matter which regime has been built since World War II. To date, it is tricky that, with deeper integration between Hong Kong and China, there are 
separated emotions and resistance. Eric thought that the appeals of localization were limited online in 2015 so the solution he suggested was working with the pro-democracy camp. Apparently, the current situation mixed with self-determination and independence offline from the younger generation is beyond Eric's expectations.

Given the above, Eric does not accept the official and mainstream versions of Hong Kong history. He keeps challenging it and provides his version.

\section{Discussion}

$\mathrm{HNH}$ is not a traditional mode of user-generated content on social media because the amount of quotation is much more than the content created. Even though he shares plenty of quotations, the most numbers of "like, share and comment" are all from his own original content. For an individual platform, the continuing writing is not easy due to the limited energy and time. How to keep writing is a problem. In addition, amid the quoted posts, lots of sources are from civil studies. Hence, the advantages and disadvantages are apparent. To the readers who like history and don't mind the length of articles, multiple sources are merits. Likewise, in the era of the internet, it is possible that his endeavor to share other nations' or regions' experiences and events as references can win stakeholders' attention and struggle for their sympathies. In other words, faced with unfixed readers in and beyond Hong Kong, an ethnic Chinese group and Chinese users can be tied. However, on the other hand, the doubts from academic against civil studies do exist. For example, Eric's opinion that indigenous people in Hong Kong are not Chinese has been attacked by a historian. How to assess the quality of civil studies and make a choice are questions as well.

Still, he attracts attention from the public, academy, and news media. In the past four years, the number of followers of the fan page continues to grow gradually and Eric has been invited to be interviewed by the media at times or give a talk in a non-government organization. These examples manifesting his efforts have been noticed. Compared with well-known politicians' and entertainers' fan pages, it is hard for HNH to attract hundreds of thousands of followers due to Eric's personal popularity and content themes. As the owner, Eric is neither a traditional opinion leader in print media era nor an internet celebrity, such as Tsao Chip and Lam Hang Chi, who became famous for writing short comments for newspapers. Roy Tsui, as an example of an internet celebrity, founded TV MOST Broadcasts Limited online to produce satirical shows. No matter whether it is comments or TV shows, both benefit from Hong Kong's historic and flourishing media field. Accordingly, HNH's topics seem too serious and concentrated. Therefore, the influences of Eric and his fan page are limited. In fact, he is more like a civic intellectual from the middle class but beyond just academic. On one hand, he runs the fan page independently. On the other hand, his articles are full of references and historical evidence.

One more question should be proposed. Since the contest between information and attention is so furious, one still needs to wait for the effect of his civil history writing. At this point, it needs to illuminate how to look at the way of civil practice online. As the paper highlights, the failure of struggling for direct suffrage in 2014 has led to a variety of political groups, advocacies and discourse emerging in recent years. In the meantime, the suppression on the pro-independence candidates in the election, the ban on radical political groups and the censorship of dissidents indicate the deterioration between society and the Hong Kong government. Thus, this paper opposes the saying that such civil practice is merely an illusion, the so-called "Hong Kong independence on keyboard", which is used to mock the actors online. Since Eric is not working in government, political parties, non-government organizations, or think tanks, his role is to prepare alternative theory/cognition for an uncertain society in the future through social media. His magazine/book tries to solve a series of tough problems, such as how to define a Hong Konger, how to locate the relations between Hong Kong and China, and the most important one of how to break the myths of China. In short, Hong Kong's problem at present can be attributed to the failure of China's nation building since the late Qing Dynasty. At this point, it is worth discovering the meaning of his behavior. 


\section{Conclusions}

The internet provides an accessible space and platform for individual to express, spread, exchange opinions, and form a loose virtual community. Through the internet, social media has become a personalized product with purpose. In order to contribute to understanding the roles of social media in identity presentation and formation in a transition society in Asia, the paper chooses almost the earliest and the most articulated fan page on the Hong Kong nation and nationalism as a case to analyze. From the beginning, in order to share four areas of history knowledge and news from the perspective of Hong Kong nationalism, Eric set up a Facebook fan page to share and disseminate his personal history writing and various events of East Asia and Southeast Asia. In terms of the form, a variety of types of posts are presented including texts, photos, web links, and video. The most numerous posts are the type of text with link. In terms of the theme, Hong Kong's information ranks in first place, but Taiwan's past experiences on localism and identity are emphasized. Multiple sources, especially from civil research and semi-media, are another salient feature. Meanwhile, the trans-platform interconnections make his writing flow without barriers. His paper book, blog post, online magazine, interviews or comments in newspaper can be accessed.

As for the limitation and further research, several directions are suggested. The paper only picks one sample to explore the roles of Facebook in identity presentation and formation. Hence, more similar fan pages in one nation/region/language and more fab pages across nations, regions and languages are available. When the context is within one community, a holistic picture can be seen; when the context is inter-communities, comparisons between groups can be made.

Funding: This research received no external funding.

Conflicts of Interest: The author declares no conflict of interest.

\section{References}

A Public Opinion Program of Hong Kong University. 2018. Survey on Hong Kong People's Ethnic Identity. December. Available online: https://www.hkupop.hku.hk/english/release/release1563.html (accessed on 30 December 2018).

Adria, Marco. 2009. Technology and Nationalism. Montreal: Kingston, London and Ithaca: McGill-Queen's University Press, p. 9. Available online: http://www.jstor.org/stable/j (accessed on 25 November 2018).

Anderson, Benedict. 2006. Imagined Communities Reflections on the Origin and Spread of Nationalism. London and New York: Verso.

Apple Daily. 2013. The First Generation Localist: Chin Wan Hijacks Movement. Available online: https: / / hk.news.appledaily.com/local/daily/article/20130528/18274808 (accessed on 20 November 2018).

Bamberg, Michael. 2012. Narrative analysis. In APA Handbook of Research Methods in Psychology. Edited by Harris Cooper, Paul M. Camic, Debra L. Long, A. T. Panter, David Rindskopf and Kenneth Sher. Washington: American Psychological Association, vol. 2, pp. 85-102. [CrossRef]

Chan, Kwok Kuen. 2016. Please Don't Confuse "Local Camp" and "Hong Kong Independence Camp". Available online: https: / / reurl.cc/WDa79 (accessed on 12 February 2019).

Chan, Chi Kit. 2017. Discursive Opportunity Structures in Post-handover Hong Kong Localism: The China Factor and Beyond. Chinese Journal of Communication 10: 413-32. [CrossRef]

Chan, Kin Man, and Vitrierat Ng. 2017. Localism, Radicalism and Cynicism in Post-Umbrella Movement Hong Kong. Mainland China Studies 60: 19-35.

Chen, Yun Chung. 2013. The Local Imagination of Open Side and Native Side. Available online: https://hk.news. appledaily.com/local/daily/article/20130529/18275711 (accessed on 22 November 2018).

Cheng, Xiang. 2018. “The Failure of Democracy Return" Must Lead to Independence. Available online: https:/ / news.mingpao.com/ins/instantnews/web_tc/article/20160415/s00022/1460690217462 (accessed on 25 November 2018).

Cheung, Tony, and Peter So. 2015. Hong Kong Nationalism Flies Off Shelves Following Leung Chun-Ying's Policy Address Criticism. Available online: http://www.scmp.com/news/hong-kong/article/1680915/hongkong-nationalism-flies-shelves-following-leung-chun-yings-policy (accessed on 22 November 2018). 
Chin, Wan. 2011. Discourse on the Hong Kong City-State. Hong Kong: Enrich Culture.

Chu, Wai Li. 2015. The arrangement of Hong Kong history. New History of National Taipei University 17: 101-6.

Chung, Kimmy. 2018. ‘No Political Considerations' Behind Chinese History Curriculum Change, Hong Kong Education Chief Says. Available online: https:/ /www.scmp.com/news/hong-kong/education/article/ 2147949/no-political-considerations-behind-chinese-history (accessed on 18 November 2018).

Demertzis, Nicolas, Stylianos Papathanassopoulos, and Antonis Armenakis. 1999. Media and Nationalism the Macedonian Question. The International Journal of Press/Politics 4: 26-50. [CrossRef]

Ding, Sheng. 2007. Digital Diaspora and National Image Building: A New Perspective on Chinese Diaspora Study in the Age of China's Rise. Pacific Affairs 80: 627-48. [CrossRef]

Earthy, Sarah, and Alexandra Cronin. 2008. Narrative Analysis. In Researching Social Life, 3rd ed. Edited by Nigel Gilbert. London: Sage.

Fearon, James D., and David D. Laitin. 2000. Violence and the Social Construction of Ethnic Identity. International Organization 54: 845-77. [CrossRef]

Fong, Brain C. H. 2017a. One Country, Two Nationalisms: Center Periphery Relations between Mainland China and Hong Kong, 1997-2016. Modern China 43: 523-56. [CrossRef]

Fong, Brain C. H. 2017b. The Rise of Localism in Hong Kong: Counter-Mobilization under the Hurricane of China Factor. Mainland China Studies 60: 1-17.

Gao, Yu Juan. 2012. Frozen History: Special Administrative Region Government's two pieces of history to Hong Kong. Culture Studies 4: 3-8.

Ho, Ming S. 2016. An Unavoidable Wave of Hong Kong Localism. Available online: http:/ /ori.upmedia.mg/ news_info.php?SerialNo=3686 (accessed on 25 November 2018).

Hui, Po K. 2013. The Political and Economic Root of Localism. Available online: http://commons.ln.edu.hk/ thinkinghk/vol2/iss1/2/ (accessed on 25 November 2018).

Huijsmans, Roy, and Thị H. L. Trần. 2015. Enacting nationalism through youthful mobilities? Youth, mobile phones and digital capitalism in a Lao-Vietnamese borderland. Nations and Nationalism 21: 209-29. [CrossRef]

Kaufman, Stuart J. 2006. Symbolic Politics or Rational Choice? Testing Theories of Extreme Ethnic Violence. International Security 30: 45-86. [CrossRef]

Khosravinik, Majid, and Mahrou Zia. 2014. Persian Nationalism, Identity and Anti-Arab Sentiments in Iranian Facebook Discourses: Critical Discourse Analysis and Social Media Communication. Journal of Language and Politics 13: 755-80. [CrossRef]

Kwong, Ying H. 2016. The Growth of "Localism" in Hong Kong a New Path for the Democracy Movement? China Perspectives 3: 63-68.

Law, Wing S. 2015. The Origins of Hong Kong's Local Identification. Available online: http://www.ln.edu.hk/ mcsln/45th_issue/criticism_08.shtml (accessed on 15 November 2018).

Lim, Chuan T. 2017. The Appearance of New Localism in Hong Kong. Available online: http://magazine. chinatimes.com/history/20170930001794-300806 (accessed on 25 November 2018).

Lin, Wei P. 2016. Internet Matsu: Online Community and the Reimagination of Place. Journal of Archaeology and Anthropology 85: 17-50.

Lin, Zhong X. 2017. Performing Identity as Politics by Other Means: Macau Netizens' Practical Experience. Mass Communication Research 131: 127-71.

Marichal, Jose. 2013. Political Facebook groups: Micro-activism and the digital front stage. First Monday 18. Available online: https:/ / firstmonday.org/ojs/index.php/fm/article/view/4653/3800 (accessed on 28 November 2018). [CrossRef]

Ming, Pao. 2015. Local Thoughts Were Born in China and Hong Kong Contradictions. Available online: https://news.mingpao.com/pns/dailynews/web_tc/article/20150115/s00001/1421258966483 (accessed on 28 November 2018).

Morris, Paul, and Edward Vickers. 2015. Schooling, politics and the construction of identity in Hong Kong: The 2012 'Moral and National Education' crisis in historical context. Comparative Education 51: 305-26. [CrossRef]

Prasad, Devi B. 2008. Content Analysis. In Research Methods for Social Work. Edited by D. K. Lal Das and Vanila Bhaskaran. New Delhi: Rawat, pp. 173-93. 
Romney, Miles, Richard G. Johnson, and Kristy Roschke. 2017. Narratives of life experience in the digital space: A case study of the images in Richard Deitsch's single best moment project. Information, Communication $\mathcal{E}$ Society 20: 1040-56. [CrossRef]

Schneider, Florian. 2018. China's Digital Nationalism. New York: Oxford University Press.

Tsui, Eric. 2017. About Me and My Hong Kong. Available online: https://sytsui.wordpress.com/2017/10/19/ my_story / (accessed on 25 November 2018).

Tynan, Caroline. 2017. Nationalism in the Age of Social Media. Available online: https://sites.temple.edu/tudsc/ 2017/12/13/twitter-bots / (accessed on 28 November 2018).

Wei, Su Ling. 2006. Hong Kong History and Identity Creation in Hong Kong Middle School History Textbooks. Unpublished Master's Thesis, National Taiwan Normal University, Taipei, Taiwan.

White, L., and A. Taket. 2000. Exploring the use of narrative analysis as an operational research method: A case study in voluntary sector evaluation. Journal of the Operational Research Society 51: 700-11. [CrossRef]

Wong, Gemma, and Mary Breheny. 2018. Narrative analysis in health psychology: A guide for analysis. Health Psychology and Behavioral Medicine 6: 245-61. [CrossRef]

( 2019 by the author. Licensee MDPI, Basel, Switzerland. This article is an open access article distributed under the terms and conditions of the Creative Commons Attribution (CC BY) license (http://creativecommons.org/licenses/by/4.0/). 